\title{
ES BALUARD, LA EDUCACIÓN Y SU RELACIÓN CON EL ÁMBITO HOSPITALARIO. PRIMERAS EXPERIENCIAS
}

\section{Es Baluard, Education in Hospitals. First experiences}

\author{
Eva Cifre \\ Es Baluard Museu d'Art Modern i Contemporani de Palma \\ difusio01@esbaluard.org
}

Recibido: 15 de junio de 2011

Aceptado: 26 de julio de 2011

\begin{abstract}
Resumen:
El artículo presenta el análisis de una experiencia educativa y artística en formato taller "Fes el teu autoretrat" ("Haz tu autorretrato", proyecto de Virginia Vallés), llevada a cabo por el Área de Educación de Es Baluard Museu d'Art Modern i Contemporani de Palma en la Unidad Pediátrica de Semicríticos del Hospital Universitario de Son Dureta. Se contextualiza a su vez la experiencia en el marco del programa del museo "Arte Contemporáneo en el Hospital" fruto de una iniciativa conjunta con otros centros de arte contemporáneo llevada a cabo desde 2009. Los beneficiarios del taller son pacientes que residen de forma permanente en el hospital. El objetivo, del programa en general y del taller descrito en particular, es el de mejorar la calidad de vida de las personas hospitalizadas rompiendo su rutina hospitalaria a la vez que propiciar un acercamiento al arte contemporáneo y a sus posibilidades expresivas. Desde la narración de la experiencia concreta defendemos el papel que están adquiriendo los museos como comunicadores socioculturales y cómo el trabajo transversal a través del arte contemporáneo puede contribuir a la mejora de la salud de las personas entendida ésta desde una perspectiva global.
\end{abstract}

Palabras clave: Calidad de vida, arte como herramienta, flexibilidad, mediador/a, trabajo transversal.

Cifre, Eva. 2011. Es Baluard, la educación y su relación con el ámbito hospitalario. Primeras experiencias. Arte Individuo y Sociedad. Vol. 23, Núm. Especial, 229-244

\begin{abstract}
:
This article explains the experience and results of an educative and artistic workshop which is called "Make your selfportrait" by artist Virginia Vallés. The experience has been running by Education Area of Es Baluard Museum in Palma de Mayorca, Spain, and Son Dureta University Hospital with Semicritics children. The experience belongs to the program "Contemporary Art in Hospitals". The program start in $2009^{\text {th }}$ and there are three Museums working on it besides Es Baluard. The aim of the program and the experience is to improve the quality of life of patients, first breaking the routine and then approaching to Contemporary Art and its expressive possibilities. Taking this experience we defend the roll museums are playing nowadays as sociocultural communicators and how Contemporary Art could be a way of working for the health of people at hospitals.
\end{abstract}

Key words: Quality of life, Art as a tool, flexibility.

Sumario: 1. Introducción. 2. Gestación del proyecto. Contexto de la acción.3. Concreción del taller. 4. Pefíl de los participantes. 5. Objetivos y planteamientos generales. 6. Desarrollo del taller: metodología, estrategias y temporalización. 7.Valoraciones y aprendizaje para futuros talleres. 8. Conclusiones. Referencias. 


\section{Introducción}

Es Baluard Museu d'Art Modern i Contemporani de Palma y su Área de Educación tienen como uno de sus principales objetivos acercar el arte contemporáneo a los diferentes públicos y colectivos, no sólo como finalidad en si misma sino también como medio para reflexionar sobre el mundo que nos rodea y desarrollar así el pensamiento y sentido crítico, a la vez que favorecer un aprendizaje significativo. El arte contemporáneo es un medio idóneo para trabajar gran cantidad de temas transversales y educar así en el respeto a la cultura y el pensamiento del otro a la vez que se descubre la riqueza y libertad creativa del lenguaje artístico contemporáneo.

Desde el Área de Educación de Es Baluard nos posicionamos desde la museología y la pedagogía crítica. Entendemos el museo como "un lugar de duda, de pregunta, de controversia y de democracia cultural" (Padró, 2003)․ Trabajamos de una manera participativa y crítica, escuchando y teniendo en cuenta las diferentes voces de los públicos con los que trabajamos como portadores de contenido y conocimiento. Trabajamos desde la cultura visual y apostamos por la interdisciplinariedad y el trabajo de contenidos transversales.

Tomando como punto de partida la misión de Es Baluard como servicio público y conscientes del creciente papel que están adquiriendo los museos como comunicadores socioculturales, convirtiéndose en un instrumento para el desarrollo de la sociedad en la que se encuentran inmersos, la intención del área es abrir el museo como un espacio de diálogo a la diversidad de colectivos que conforman la ciudadanía, para que así se convierta en un espacio de la comunidad que favorezca la inclusión.

Así, desde su apertura, en enero de 2004, desde el Área de Educación programamos diferentes actividades dirigidas a todo tipo de públicos.

La relación con el ámbito hospitalario ha evolucionado paralelamente a la consolidación del Área de Educación desde la inauguración del museo hasta hoy.

En un primer momento nos limitamos a acciones puntuales destinadas a satisfacer la demanda de visitas guiadas a las exposiciones por parte de diversas unidades hospitalarias, las cuales son susceptibles de desplazarse hasta el museo (unidades del área de salud mental, unidad de trastornos alimenticios...).

El punto de inflexión en esta relación viene marcado el 2008 por el trabajo en red que establecimos con los servicios educativos del Centre d'Art La Panera de Lleida y el CDAN de Huesca. Durante 2008-09 se lleva a cabo el proyecto "Red de intercambio entre programas de educación especial de centros de arte contemporáneo de la Eurorregión Pirineos-Mediterráneo"2 y gracias a este programa iniciamos relaciones determinantes para posteriores proyectos del Área de Educación.

${ }^{1}$ PADRÓ, Carla. "La museología como forma de reflexionar sobre los museos como zonas de conflicto e intercambio”. En: LoRente, Jesús Pedro. Museología crítica y Arte contemporáneo. Zaragoza: Prensa Universitaria de Zaragoza, 2003.

${ }^{2}$ Véase los resultados del proyecto en "Intercambio entre programas de educación especial de centros de arte contemporáneo de la Eurorregión Pirineos-Mediterráneo". En AA.VV. Arte Contemporáneo y Educación Especial. Huesca: Ajuntament de Lleida, Centre d'Art La Panera, CDAN. Centro de Arte y Naturaleza. Fundación Beulas y Fundació Es Baluard Museu d'Art Modern i Contemporani de Palma, 2010. 
Por una parte con el Grupo de Investigación en Escuela Inclusiva y Diversidad de la Facultad de Educación de la Universitat de les Illes Balears y por otra con el Área Hospitalaria de Salud Mental de Gesma (Gestió Sanitària de Mallorca) ${ }^{3}$.

Después de realizar diversas actividades y talleres con los pacientes ingresados en el área hospitalaria, satisfechas ambas partes con los resultados y objetivos obtenidos, en octubre de 2010 se firma un convenio entre Es Baluard y Gesma para consolidar la relación, fijar la metodología y dar continuidad a las acciones (convenio vigente en la actualidad $)^{4}$.

Animados por los resultados de este primer trabajo en red de centros de arte, en 2009 nos planteamos el reto de acercar el museo y la creación contemporánea al ámbito hospitalario. Una nueva ayuda de la Eurorregión apoyaba la iniciativa. Nuevamente trabajamos juntos Es Baluard, el Centre d'Art La Panera y el CDAN. Entre los objetivos generales y comunes del proyecto que titulamos "Arte Contemporáneo en el Hospital" encontramos:

Acercar las prácticas artísticas contemporáneas al ámbito hospitalario.

Mejorar la calidad de vida de los pacientes y romper con la rutina hospitalaria.

Recibir formación y asesoramiento por parte de profesionales del ámbito sanitario sobre las políticas y procedimientos de actuación en los hospitales.

Promover y aumentar la participación activa del personal sanitario y de los pacientes en los proyectos desarrollados.

Valorar el impacto de las actividades sobre los pacientes, personal sanitario y profesionales de los museos.

El proyecto estaba concebido con una doble vertiente, por una parte formativa, para que los diferentes departamentos educativos de los centros participantes pudiéramos:

Conocer el estado de la cuestión en esta materia en el ámbito del Estado español y el modelo francés Art et hôpital ${ }^{5}$.

Trabajar conjuntamente para poder establecer unas pautas y vías posibles de actuación.

Ser conscientes de las distintas realidades territoriales, en nuestro caso, la red sanitaria de las Illes Balears y su estructura para poder estudiar las posibilidades de intervención por parte de Es Baluard.

Para ello realizamos distintas mesas de trabajo y estancias formativas tanto en Francia como en Lleida con la presencia de profesionales en el sector sanitario y/o artístico con experiencia en el campo hospitalario.

\footnotetext{
${ }^{3}$ Gesma es una empresa pública integrada en el Servicio de Salud de la Consejería de Salud y Consumo del Govern de les Illes Balears, la cual presta atención sociosanitaria y de salud mental, preferentemente a personas con Trastorno Mental Grave.

${ }^{4}$ Véase el inicio de la relación entre ambas entidades en GonZÁlez Guillén, Alicia. "El arte como herramienta para mejorar la salud mental". ”. En AA.VV. Arte Contemporáneo y Educación Especial. Huesca: Ajuntament de Lleida, Centre d'Art La Panera, CDAN. Centro de Arte y Naturaleza. Fundación Beulas y Fundació Es Baluard Museu d'Art Modern i Contemporani de Palma, 2010.

${ }^{5}$ Convenio firmado en el 2000 entre los ministerios de Cultura y Sanidad con el objetivo de hacer accesible la cultura a diferentes sectores de público. Desde el 2010 este convenio ha sido substituido por el de Culture Santé.
} 
Por otra parte el proyecto pretendía realizar proyectos educativos y artísticos a largo plazo en el ámbito sanitario que nos posibilitaran trabajar desde el arte contemporáneo con la participación de las diferentes voces implicadas.

Fruto de este programa surgieron dos talleres a largo plazo con colaboradores externos al Área de Educación de Es Baluard. En primer lugar, el taller "Náufragos", proyecto de la artista Isabel Castro en el que participaron 6 usuarios de la Unidad de Media Estancia "Lluerna" del Área Hospitalaria de Salud Mental de Gesma. Y un segundo taller, "Fes el teu autoretrat" ("Haz tu autorretrato") con la Unidad Pediátrica de Semicríticos del Hospital Universitario Son Dureta ${ }^{6}$, proyecto de Virginia Vallés, profesora de educación artística.

Será este segundo taller, su contexto, desarrollo y conclusiones el que centrará nuestro artículo."FES EL TEU AUTORETRAT" ("HAZ TU AUTORRETRATO")

El programa "Arte contemporáneo en el hospital" creaba el marco y proporcionaba los recursos al Área de Educación de Es Baluard para plantearnos la realización de un "taller de artista" en el ámbito hospitalario. No se trataba, como en otras ocasiones, de trabajar con pacientes de una u otra unidad en el museo, sino de sumergirnos en el mundo hospitalario, desconocido por nosotros hasta el momento. Trabajar fuera del museo, concebido como espacio físico, cerrado y acercar la creación artística contemporánea a un público que no se podía desplazar, darles a conocer las posibilidades expresivas del arte contemporáneo... El proyecto nos obligaba a cambiar de espacio e incluso de rol, éste era el reto al que nos enfrentábamos con ilusión por una parte, pero con cierta inseguridad y temor por la otra.

\section{Gestación del proyecto - Contexto de la acción}

Conscientes de que iniciábamos un nuevo camino y de que en las negociaciones previas, la preparación y planificación del taller, así como en la correcta elección del colaborador o colaboradora radicaba el éxito o no de la iniciativa dedicamos meses a toda la parte que podríamos llamar de gestación del proyecto o de mediación entre las diversas partes implicadas.

Gracias a la formación previa que nos había proporcionado el proyecto de la Eurorregión teníamos referentes de actuaciones similares en el ámbito español y conocimientos del modelo francés Art et hôpital, muy lejano, sin embargo, a nuestra realidad. Desconocíamos actuaciones similares en las Illes Balears, que sentaran precedentes en lo que respecta a la entrada de una institución artística en el contexto hospitalario para trabajar a partir del arte con los pacientes, en el hospital.

${ }^{6}$. Desde finales de 2010, Hospital Universitario Son Espases. 
La vía de entrada al hospital la encontramos, curiosamente, de manos del Grupo de Investigación en Escuela Inclusiva y Diversidad de la Facultad de Educación de la Universitat de les Illes Balears ${ }^{7}$ y de su programa INeDITHOS (Intervención e Investigación para la Inclusión Educativa y Tecnológica dentro del ámbito Hospitalario $)^{8}$.

Nuestro contacto y relación con la universidad hizo que conociéramos la existencia de la Unidad Pediátrica de Semicríticos en el Hospital Universitario Son Dureta en la que se encontraban hospitalizados, según nos informaron en ese momento, un chico y dos niñas con carácter permanente, es decir, su lugar de residencia era el mismo hospital. Decidimos que a esa unidad y a esos pacientes destinaríamos los recursos que se nos ofrecían por parte de las ayudas de la Eurorregión, entendiendo que si nuestra intención inicial era acercar la creación artística contemporánea y sus capacidades expresivas a personas que no pudieran desplazarse hasta el museo a la vez que romper la rutina hospitalaria y mejorar la calidad de vida de los pacientes hospitalizados, no podíamos pensar en mejores destinatarios para dirigir esa acción que personas cuyo mundo se limita al ámbito hospitalario.

Las negociaciones en un primer momento se hicieron en dos sentidos: por una parte, con los profesores responsables del programa INeDITHOS y los alumnos colaboradores encargados del día a día del programa; y por otra, la labor de seleccionar un colaborador o colaboradora adecuados para llevar a cabo el proyecto. Buscábamos a una persona del ámbito artístico pero también con experiencia en el mundo educativo, flexible, sensible y con ilusión por afrontar el reto que le presentábamos. Encontramos esta figura en la persona de Virginia Vallés, licenciada en Bellas Artes y profesora de educación artística, de quien destacamos su profesionalidad y entusiasmo vertidos en el proyecto desde el primer momento.

Una vez seleccionada la unidad hospitalaria a la que nos dirigiríamos y la artista a quien se encargaría el proyecto, fue el momento de poner en relación a todas las partes implicadas. Después de varios encuentros y de visitar el hospital para conocer la unidad, los pacientes, sus características, su espacio y entorno, Virginia nos presentó el proyecto en formato taller "Fes el teu autoretrat".

\footnotetext{
${ }^{7}$ Existe desde 2009 un convenio de colaboración entre ambas entidades para el trabajo conjunto hacia la accesibilidad de los distintos programas del Área de Educación de Es Baluard.

${ }^{8}$ Proyecto que se lleva a cabo desde el curso 2002-03 en el Hospital Universitario Son Dureta con la intención de dar respuesta a las necesidades psico-socio-educativas de los pacientes de la Unidad Pediátrica de Semicríticos y así intentar mejorar su calidad de vida y prestar un servicio de apoyo a sus familias.
} 


\section{Concreción del taller}

El taller, a grandes rasgos, se concretó de la siguiente manera:

Título: "Fes el teu autoretrat" ("Haz tu autorretrato")

Participantes: Pacientes de la Unidad Pediátrica de Semicríticos del Hospital Universitario Son Dureta (Palma)

Proyecto: Virginia Vallés, profesora de educación artística

Coordinación y seguimiento: Área de Educación de Es Baluard (Eva Cifre, Mar Barceló y Sebastià Mascaró)

Colaboradores y mediadores: Responsables y estudiantes voluntarios del programa INeDITHOS (Sebastià Verger, Miquel Salom y Laura Ortiz)

Temporalización: 5 sesiones de 2 horas llevadas a cabo entre el 6 de febrero y el 5 de marzo de 2010

\section{Perfil de los participantes}

Pacientes de la Unidad Pediátrica de Semicríticos del Hospital Universitario de Son Dureta (Palma). En concreto se trataba de 2 participantes de 8 y 18 años que presentan pluripatologías con afectaciones motoras, respiratorias y sistémicas que provocan la dependencia de los pacientes de cuidados continuos (atención constante del personal sanitario, respiración asistida, alimentación por sonda, monitorización...).

El usuario de más edad, padece una tetraplejia agravada por el hecho de necesitar respiración asistida. Además, por las circunstancias concretas vividas, presenta un estado de frustración consigo mismo y con las maestras que le atendían cuando iba al Aula Hospitalaria. Su compleja situación ha derivado en una total apatía, desinterés, falta de motivación y un bajo nivel de autoestima que provoca una falta de interés por todo aquello que requiera una implicación por su parte, ya sea por lo que se refiere a tareas escolares o a las relaciones personales. Su nivel cognitivo es bueno. En raras ocasiones ha salido del hospital a lo largo de su vida?.

La paciente más joven presenta una miopatía congénita severa de tipo nemalínico. Presenta un cuadro tetrapléjico aunque tiene movilidad reducida en los dedos tanto de las manos como de los pies. Necesita respiración asistida, utilizar una sonda gástrica y un aparato buco-fonador que no limita el habla pero sí su articulación. Su nivel cognitivo está dentro de la media para su edad. Está escolarizada en un centro público de integración preferente para personas con discapacidad motora. Por tanto cada día va y viene del hospital al colegio $^{10}$.

\footnotetext{
${ }^{9}$ Salom Rigo, M., Ortiz Sola, L. y Verger Gelabert, S. "Vivir en un hospital. El caso de Ramón”. XVIII Congreso Internacional INFAD: Desafíos y perspectivas actuales de la Psicología, Roma, 13-16 abril 2011.

${ }^{10}$ Ortiz Sola, L., Salom Rigo, M. y Verger Gelabert, S. "Un mundo dentro de un hospital. Estudio de caso: Ainhoa." XVIII Congreso Internacional INFAD: Desafíos y perspectivas actuales de la Psicología, Roma, 13-16 abril 2011.
} 


\section{Objetivos y planteamientos generales}

Como ya hemos mencionado anteriormente, los objetivos generales que nos planteábamos eran:

Romper la rutina hospitalaria.

Relacionarse con personas distintas a las habituales.

Conocer las posibilidades del arte contemporáneo como medio de expresión.

La propuesta de Virginia se basaba en el poder mediador del arte contemporáneo y por tanto proponía la siguiente pregunta como punto de partida:

“Cómo estos niños dan sentido al mundo y se comunican con él?”

Poder llevar esta pregunta a la práctica significaba organizar experiencias de aprendizaje que permitieran conseguir los siguientes objetivos específicos:

Realizar valoraciones y mostrarlas gráficamente mediante la creación artística.

Comunicarse utilizando lenguajes y formas de comprensión diferentes.

Conseguir conocer algunos alfabetos visuales.

A la hora de diseñar las actividades era muy importante tener en cuenta las necesidades de los participantes a la vez que sus especificidades, como por ejemplo que su escasa o nula movilidad nos hacía centrar el trabajo con ellos a su capacidad de decisión.

Se trataba de poner en relación la propia experiencia de los participantes, su subjetividad, con los alfabetos visuales aprendidos, de manera que pudieran transformar y aplicar las prácticas visuales a nuevos contextos dando la posibilidad de elaborar y crear narrativas visuales por procesos y medios diversos. Todo ello se traducía y materializaba en la realización de un autorretrato por parte de los participantes a partir del análisis de su entorno, sus gustos y preferencias.

\section{Desarrollo del taller: metodología, estrategias y temporalización}

El taller se presentaba dividido en tres fases: captación de preconceptos, trabajo de investigación y aplicación de la información, a las que tenemos que añadir, una vez realizado el taller, la fase de visibilidad del proyecto.

\section{$\mathbf{1}^{\mathrm{a}}$ sesión (captación de preconceptos)}

La intención de la sesión consistía, como si de un juego de cartas se tratara, en que los participantes se familiarizaran con diversos artistas contemporáneos y distintos lenguajes artísticos. A su vez se introducía el trabajo a desarrollar a partir de entonces y todas las posibilidades que tenían a su alcance.

Se presentó a los pacientes un juego de cartas diseñado por Virginia donde había representados diferentes elementos como objetos, autorretratos reconocidos de ar- 
tistas contemporáneos, referencias a lenguajes artísticos distintos (pintura, collage, fotografía...).

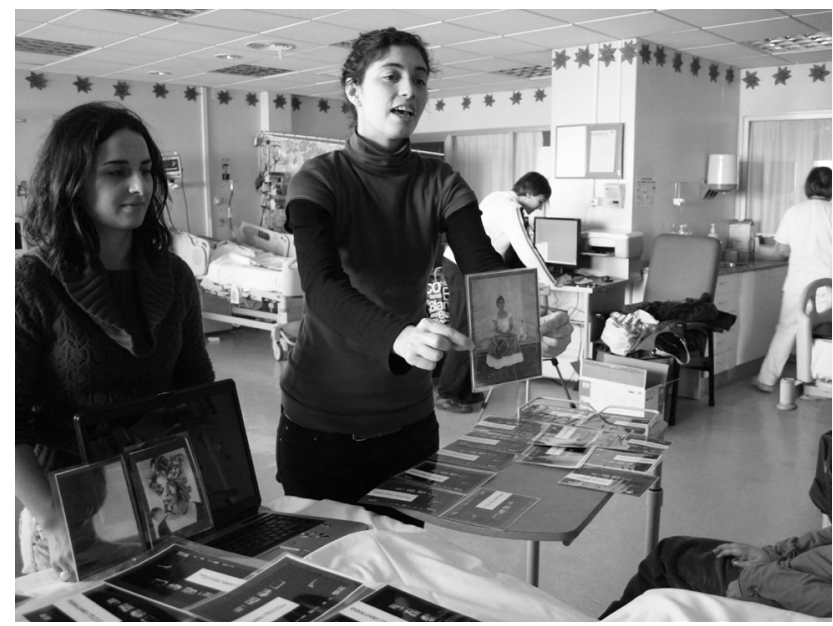

Fig.1

Al final de la sesión cada uno de ello eligió los autorretratos que más les gustaron, con los que se sintieron más identificados. Estos quedaron colgados en su habitación hasta la próxima sesión. Decidieron que el espacio más adecuado para que tuvieran acceso a ellos era el techo.

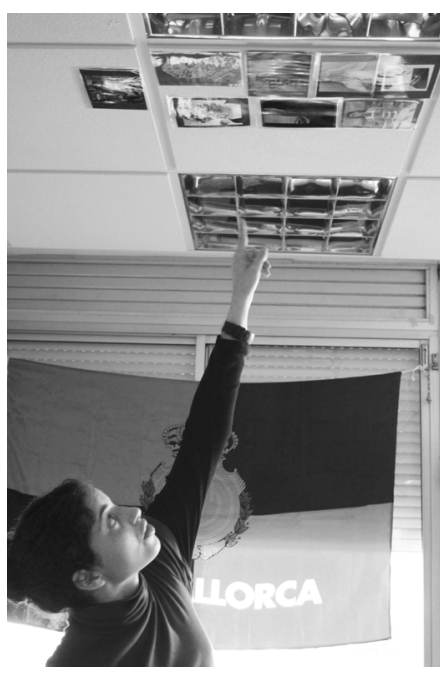

Fig.2

$2^{\mathrm{a}} \mathbf{y ~}^{\mathrm{a}}$ sesión (trabajo de investigación)

En estas sesiones los participantes procedieron a analizar su contexto inmediato y su contexto externo. 
¿Cómo se relacionan con su contexto más inmediato? Se trabajó la respuesta a partir de los objetos que tienen en su habitación: fotografías, pósters, muñecas... Nos contaron cuales son las experiencias que los hacen especiales.

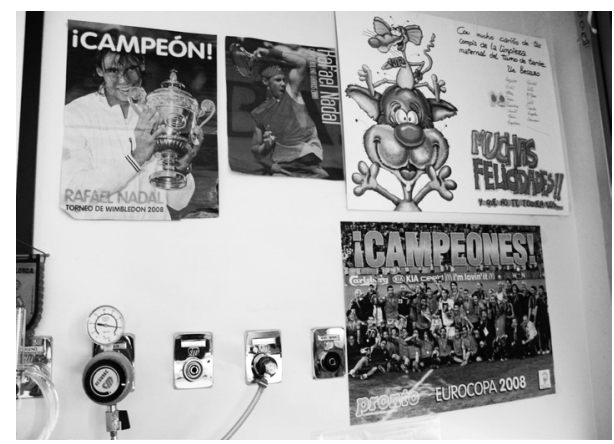

Fig. 3.

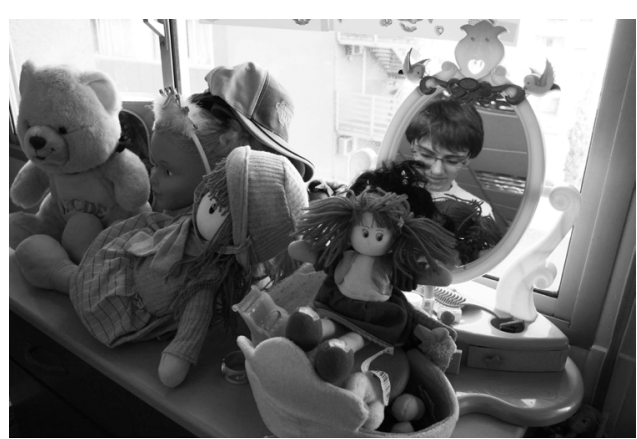

Fig.4

También trabajamos su relación con el contexto externo a partir de sus relaciones personales con familiares, personal sanitario, Internet, televisión, música... Paralelamente a estas conversaciones se fueron eligiendo elementos que se incorporarían a su autorretrato. El proyector y el papel continuo sobre el que dibujar o perfilar lo proyectado resultaron piezas clave a lo largo del proceso.

El participante de más edad ¡nunca había visto su sombra! Proyectamos y dibujamos su perfil para que formara parte de su autorretrato, proyectamos y dibujamos las imágenes y fotografías elegidas por él.

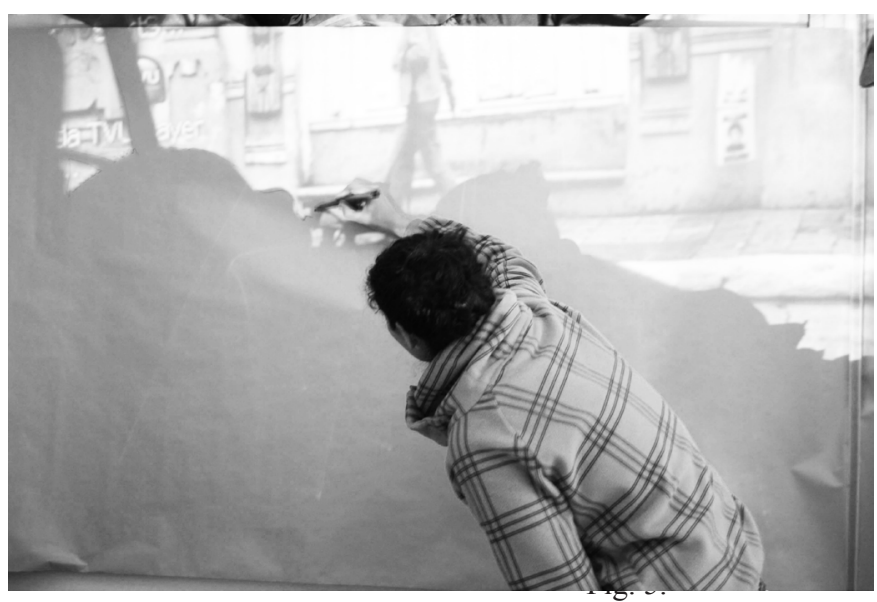

La participante más joven decidió incorporar un caballo a su autorretrato. Puesto que tiene movilidad en sus dedos ella misma lo seleccionó de Internet, lo coloreó con el ratón del ordenador y posteriormente se proyectó en la pared para dibujarlo. Conseguió colorearlo con pintura gracias a unos pinceles de dedo adaptados, actividad que le reportará gran satisfacción. 


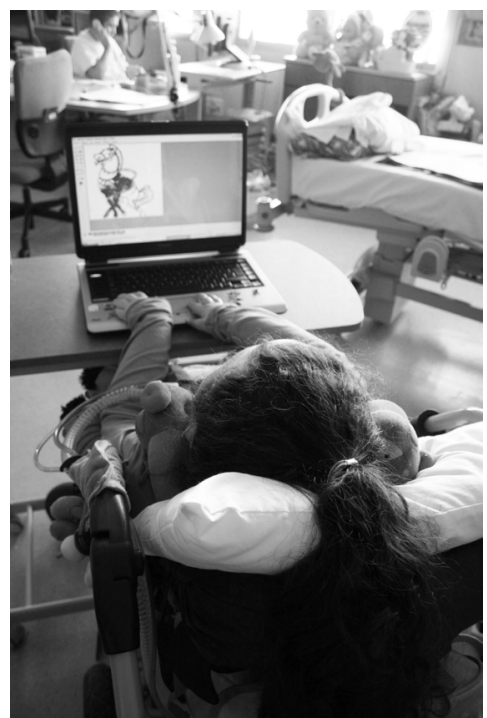

Fig.6

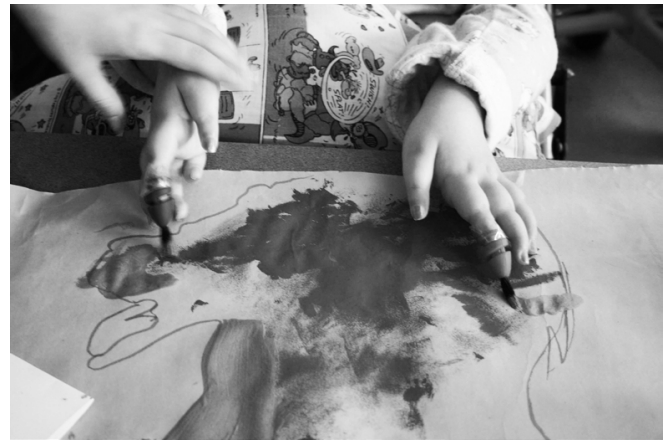

Fig.7

También dejamos marcada la huella de su silla de ruedas pintándola con pintura pastel y deslizándola sobre el papel continuo.

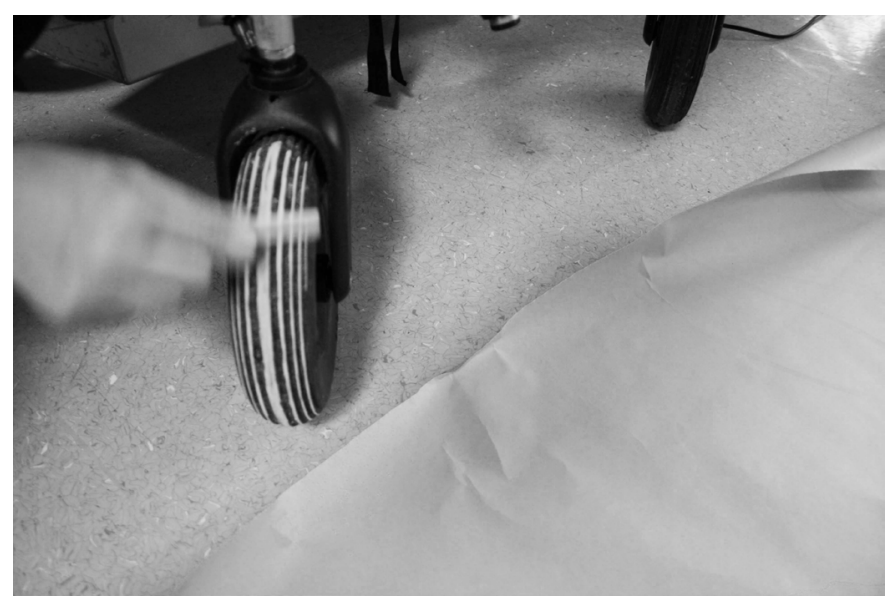

Fig.8.

$4^{\mathrm{a}}$ y $5^{\mathrm{a}}$ sesión (aplicación de la información)

En las dos últimas sesiones previstas se procedió a ir materializando el autorretrato a partir de los elementos elegidos en las sesiones previas, elementos que les gustaban, que les identificaban, que contaban cosas sobre ellos. 
Decidieron la composición del mismo y se procedió a llevarla a la práctica (voluntarios del programa INeDITHOS, educadores del museo y Virginia). Se fueron incorporando los distintos elementos, dibujos, proyecciones, fotografías, pensaron en un fondo donde ubicarse... todo ello se compuso a modo de collage sobre un cartón pluma de $1 \mathrm{~m} \times 70 \mathrm{~cm}$.

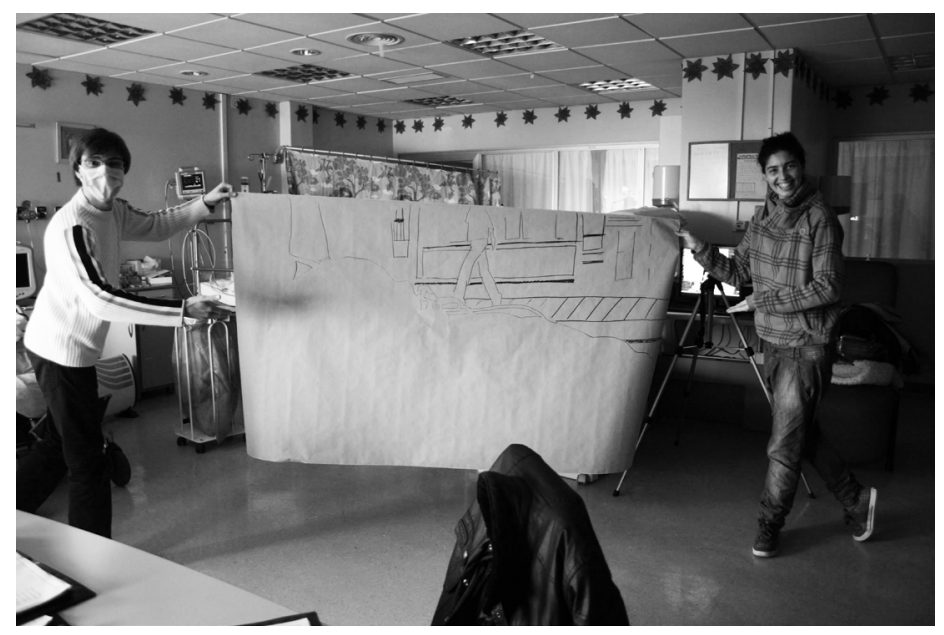

Fig.9

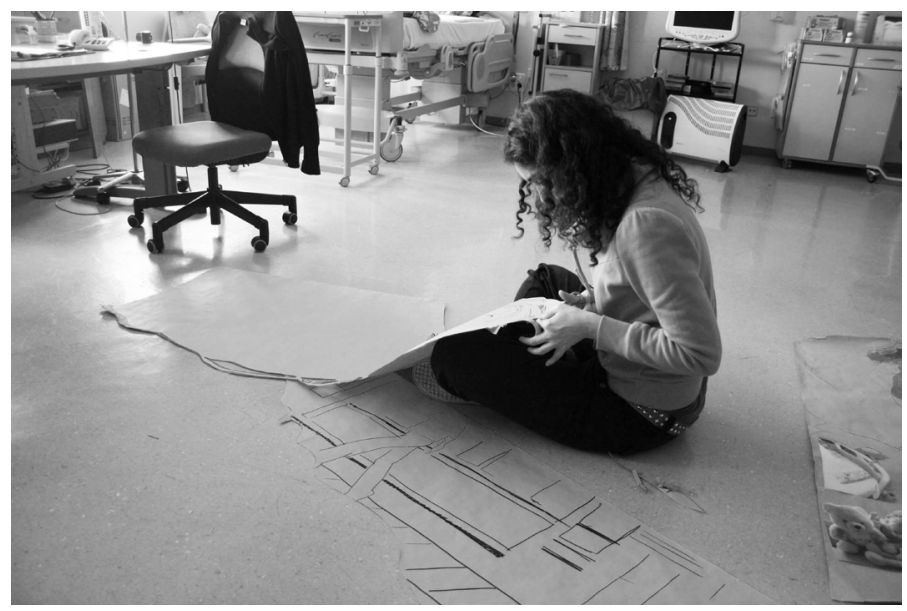

Fig10 


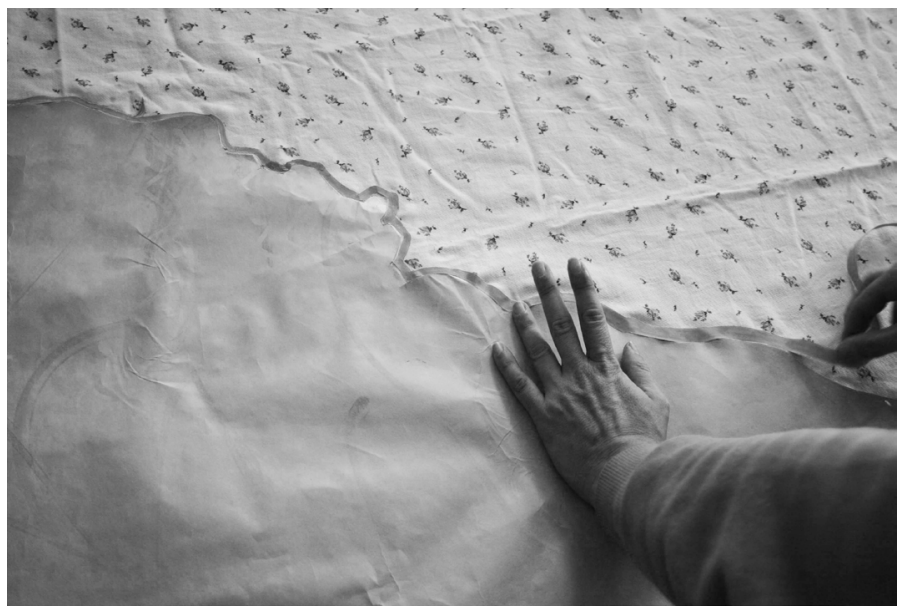

Fig.11

Curiosamente y rompiendo con nuestras expectativas la mayor parte de los elementos que les autorretratan proceden de entornos que no encontramos dentro de su habitación (caballos, la playa, el mundo del deporte, grupos de música...).

\section{$\mathbf{6}^{\mathbf{a}}$ sesión (visibilidad del proyecto)}

Esta sesión, no prevista en un inicio, tiene lugar para hacer entrega a los participantes de su autorretrato y concluir el taller. Como el autorretrato original, collage sobre cartón pluma, era demasiado incómodo para tenerlo en la habitación se decidió hacer un ploter de la obra para que la pudieran colgar desde su habitación y así mostrar su autorretrato a través de su ventana al mundo.

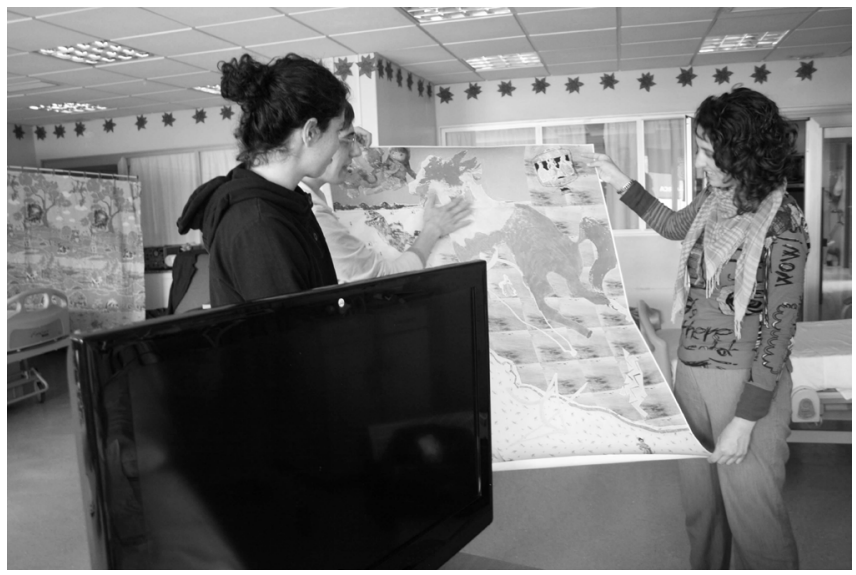

Fig. 12

Una de las cosas que más nos impactaron en la primera visita a la unidad, previa al taller, fue ver como desde la calle se veían sus ventanas, la bandera de su equipo de fútbol favorito, los adornos navideños propios de la época del año en que tuvo lugar 
esa primera visita... Las ventanas de la Unidad Pediátrica de Semicríticos eran distintas a las del resto del hospital, mostraban parcelas de sus habitantes, tenían vida... Por eso decidimos entre todos que una bonita forma de dar visibilidad al proyecto era que mostraran sus autorretratos a través de su ventana física al mundo y a través de su ventana virtual, Internet, de manera que sus autorretratos con la explicación que ellos construyeron fueron colgados en la página web del museo.

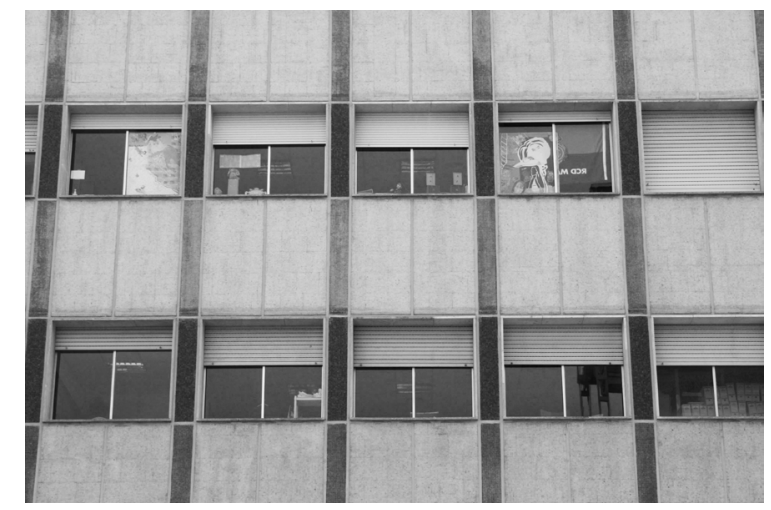

Fig.13

Resultados autorretratos y explicación de los participantes

Posteriormente a esta última sesión, los participantes junto con los voluntarios del programa INeDITHOS trabajaron en el texto explicativo que aparecería junto a su autorretrato en la web y que tenemos a continuación. Esta sesión con los voluntarios sirvió para evaluar la actividad por parte de sus participantes.

\section{Buceando en el mar de mujeres de $R$ Autorretrato $\mathrm{R}$}

"Mirando autorretratos de otros autores elegí aquellos en los que me sentía más identificado $\mathrm{y}$, sobre todo, fue la fuente de inspiración para poder hacer el mío. Tuve que empezar a pensar en todas aquellas cosas y personas que están cerca de mí, que me gustan... pensar sobre mí mismo. Al final, la parte que me gustó más fue la de colocar cada una de las imágenes en su sitio... En mi autorretrato se me puede ver a mí, un poco tapado por las cosas y personas que me acompañan y me gustan, sobre todo mujeres, ¡de ahí su título!"

\section{Paseando con un caballo por la playa Autorretrato A}

"Me encantan la playa y los caballos, pero también las princesas (son tan guapas...). Todo ello debería estar en mi autorretrato porque me gusta y un autorretrato es para describirme a mí misma. Me ha gustado hacer mi autorretrato porque he tenido que pensar en lo que me gusta (y también lo que no me gusta). He conocido a gente nueva y lo he pasado muy bien." 


\section{Valoraciones y aprendizaje para futuros talleres}

En el momento de concluir el taller, el sentimiento de todas las partes implicadas en el mismo era de satisfacción. Satisfacción por haber llevado a cabo una acción que por lo novedoso de la misma, teniendo en cuenta nuestro contexto y realidad, nos planteaba un reto. Satisfacción por haber alcanzado los objetivos marcados al inicio de la actividad. Y satisfacción por la respuesta generada en los participantes, a pesar del estado de ánimo de uno de ellos y de sus altos y bajos durante el desarrollo de la actividad, él mismo valoraba positivamente la acción llevada a cabo y así lo reflejaba en la explicación final de su autorretrato.

Fruto de esta primera experiencia de inmersión y actuación en el ámbito hospitalario obtuvimos una serie de aprendizajes y valoraciones a tener en cuenta cara a futuras experiencias.

La primera realidad a la que tuvimos que enfrentarnos fue la dificultad para encontrar "espacios" en la dinámica hospitalaria, y el primer aprendizaje, en consecuencia, la importancia de la flexibilidad, la necesidad constante de adaptar las sesiones y ajustar las programaciones. La fluidez en las distintas sesiones no siempre era la deseada, tanto por las características de los propios participantes como por cuestiones ajenas al desarrollo del taller. Este hecho suponía un reajuste constante en el diseño de las sesiones respecto a como se habían concebido en un principio. Para ello se hacían reuniones previas a cada sesión por parte de la conductora del taller, el Área de Educación de Es Baluard y los voluntarios del programa INeDITHOS.

La comunicación con el personal del hospital no fue la deseada. Los interlocutores con el personal sanitario eran los voluntarios y a pesar de los esfuerzos realizados, no siempre se obtenía la respuesta esperada. Los turnos rotativos a que está sometido el personal sanitario, no sólo impedían que hubiera un seguimiento, continuidad o implicación por su parte, sino también, en ocasiones, una obstaculización al desarrollo del taller al no ser conscientes de los tiempos marcados para su desarrollo, y por tanto al no tener los pacientes preparados para la actividad. Quizá el error por nuestra parte fue limitar la relación con el ámbito hospitalario a la "permisividad" para que la acción se desarrollara, en lugar de intentar implicarlo en la misma de tal manera que hubieran sido partícipes de los avances y beneficios obtenidos con los pacientes.

Por otra parte, valoramos como imprescindible el trabajo conjunto y el seguimiento y participación al taller de los voluntarios de INeDITHOS, no sólo porque actuaron de intermediarios entre Es Baluard y el personal sanitario, y favorecieron el marco para que el taller se llevara a cabo, sino por su relación y conocimiento de los pacientes que iban a participar. Ello hace que creamos necesaria la acción conjunta con ellos cara a futuras acciones en la unidad y nos planteemos la importancia de encontrar una figura mediadora entre las partes (para acciones futuras en otras unidades), tanto en las negociaciones como en el seguimiento y participación de la acción, figura que puede materializarse en distintos perfiles según el caso (profesionales, familiares, voluntarios...).

Por último, hacer hincapié en el sentimiento de inseguridad y desconfianza con el espacio y la situación de los pacientes, común tanto por parte del equipo de Es Baluard como de Virginia. Con el paso de las sesiones este sentimiento, aunque no 
desapareció, desembocó en otro; surgió la necesidad manifiesta por parte del equipo, ante los resultados obtenidos, de dar continuidad al programa, de establecer una relación permanente y continua con los pacientes de la unidad. Que la acción llevada a cabo no se limitara a un hecho puntual. Los logros obtenidos en todos los niveles debían consolidarse dando estabilidad al programa.

Ese mismo verano, al ser apoyada la iniciativa por parte de INeDITHOS, llevamos a cabo un nuevo taller en la unidad. En esta ocasión se trató de una adaptación por parte del equipo educativo del museo de uno de los talleres que habíamos desarrollado durante el curso con público familiar. El taller se titulaba "Sembra el teu paradís" ("Siembra tu paraíso") y tenía como punto de partida la instalación de Joana Vasconcelos, Garden of Eden 2 que tuvo lugar en el Aljub de Es Baluard. En este caso proponíamos a los participantes crear su propio paraíso a partir del análisis de su estado ideal y de la reflexión a partir de los cinco sentidos. El paraíso de cada uno de ellos se materializó en un móvil para su habitación. Una vez más, con las características de los usuarios ya mencionadas, la reflexión, el debate de ideas y su capacidad de elección fueron los puntos clave para el desarrollo del taller.

\section{Conclusión}

Si tomamos como punto de partida para nuestra reflexión final la definición de salud ofrecida por la Organización Mundial de la Salud (OMS) según la cual se entiende por salud al "estado de completo bienestar físico, mental y social, y no solamente la ausencia de afecciones o enfermedades", sentimos que con acciones como la descrita en el presente artículo, también desde una institución artística o cultural se puede contribuir al bienestar de las personas y por tanto a su salud. Es significativo como el trabajo a partir del arte contemporáneo, al favorecer y fomentar el trabajo en la dimensión emocional, social e intelectual de la persona, tratando aspectos como la expresión de sentimientos, el desarrollo personal, la autoestima y la relación con los demás aporta satisfacción a los participantes y por tanto contribuye a mejorar su salud entendida desde esta perspectiva global.

Es Baluard, consciente de todo ello, apuesta por la continuidad de los programas iniciados en este campo, tanto con la Unidad Pediátrica de Semicríticos del Hospital Universitario de Son Dureta como con el Área de Salud Mental de Gesma, a la vez que se plantea el reto de abrir esta línea de actuación a nuevas unidades dentro del ámbito sanitario general para que así se puedan beneficiar el mayor y más diverso número de personas posibles. Somos conscientes de que para ello queda todavía mucho camino por recorrer y mucho trabajo que realizar para lograr un mayor acercamiento entre instituciones culturales y sanitarias. 


\section{Referencias}

AA.VV. 2010: Arte Contemporáneo y Educación Especial. Huesca: Ajuntament de Lleida, Centre d'Art La Panera, CDAN. Centro de Arte y Naturaleza. Fundación Beulas y Fundació Es Baluard Museu d'Art Modern i Contemporani de Palma.

Ortiz, L., Salom, M. y Verger, S. 2011: Un mundo dentro de un hospital. Estudio de caso: Ainhoa. Trabajo presentado en XVIII Congreso Internacional INFAD: Desafíos y perspectivas actuales de la Psicología, Abril, Roma.

Padró, C. 2003: La museología como forma de reflexionar sobre los museos como zonas de conflicto e intercambio. En Lorente, J., Museología crítica y arte contemporáneo. Zaragoza: Prensa Universitaria de Zaragoza

Salom, M., Ortiz, L. y Verger, S. 2011: Vivir en un hospital. El caso de Ramón. Trabajo presentado en XVIII Congreso Internacional INFAD: Desafíos y perspectivas actuales de la Psicología, Abril, Roma 